"This document is the Accepted Manuscript version of a Published Work that appeared in final form in J. Am. Chem. Soc. 2016, 138, 11970-11978, copyright (C American Chemical Society after peer review and technical editing by the publisher. To access the final edited and published work see DOI: 10.1021/jacs.6b07382. This article may be used for non-commercial purposes in accordance with the ACS guidelines published at http://pubs.acs.org/page/policy/articlesonrequest/index.html]." 


\title{
Stereoselective and Versatile Preparation of Tri- and Tetra-Substi- tuted Allylic Amine Scaffolds under Mild Conditions
}

\author{
Wusheng Guo,§ Luis Martínez-Rodríguez,§ Rositha Kuniyil,§ Eddy Martin,§ Eduardo C. Escudero- \\ Adán,§ Feliu Maseras*,+,§ and Arjan W. Kleij*,§,‡ \\ SInstitute of Chemical Research of Catalonia (ICIQ), the Barcelona Institute of Science and Technology, Av. Països Catalans \\ 16, 43007 - Tarragona, Spain \\ †Departament de Química, Universitat Autònoma de Barcelona, 08193 Bellaterra, Catalonia, Spain \\ ${ }^{\ddagger}$ Catalan Institute of Research and Advanced Studies (ICREA), Pg. Lluís Companys 23, 08010 - Barcelona, Spain
}

\begin{abstract}
Significant progress has been observed in recent years in the synthesis of allylic amines which are important building blocks in synthetic chemistry. Most of these processes are effective towards the preparation of allylic amines with limited potential to introduce three or four different substituents on the olefinic unit in a stereocontrolled fashion. Therefore, the discovery of a mild and operationally simple protocol allowing such challenging stereoselective synthesis of multi-substituted allylic amines remains an inspiring target. Herein, we report the first general and practical methodology for the stereoselective synthesis of tri- and tetra-substituted allylic amines based on Pd-catalyzed conversion of allyl surrogates readily obtained from cyclic vinyl carbonates. These rare conversions are characterized by excellent stereoselectivity, operational simplicity, mild reaction conditions and wide scope in reaction partners. DFT studies were performed to rationalize the stereocontrol in these allylic amine formation reactions, and evidence is provided that the formation of a six-membered palladacyclic intermediate leads towards the formation of $(Z)$-configured allylic amine products.
\end{abstract}

\section{- INTRODUCTION}

Highly stereoselective construction of multi-functionalized tri- and tetra-substituted olefin scaffolds continues to be highly challenging. ${ }^{1}$ Allylic amines, representing a class of functional olefins, are fundamental building blocks in organic chemistry and their synthesis is an important industrial and synthetic goal. ${ }^{2}$ Metal catalyzed conversion of allylic compounds has emerged as a powerful and practical methodology for the construction of $(E)$-selective, $\gamma$-mono-substituted allylic amine scaffolds (Scheme 1, route $\mathbf{I}$ ). The most attractive routes towards such allylic amines include conventional allylic substitution reactions, ${ }^{3}$ the hydroamination of dienes, ${ }^{2 \mathrm{~g}, 4}$ and more recently developed $\mathrm{C}-\mathrm{H}$ bond activation/functionalization strategies. ${ }^{5}$ Despite notable progress in this area, the development of a general methodology towards a stereoselective synthesis of highly functionalized tri- and tetra-substituted allylic amines based on metal catalyzed "allylic chemistry" (route II) presents a fundamental and practical challenge yet not resolved. ${ }^{6}$ Generally, the stereocontrolled introduction of different substituents in an olefin unit represents a huge challenge. Various methodologies towards the formation of $\gamma$-disubstituted allylic amines have been developed (Scheme 1a, route $\mathbf{I I} ; \mathrm{R}^{3}=\mathrm{R}^{4}=\mathrm{Me}$ in most reported cases $)^{3 \mathrm{~m}-\mathrm{o}, 4 \mathrm{a}-\mathrm{d}, 7}$ avoiding the formation of stereochemical mixtures and leaving rather limited potential for postfunctionalization.

Limited methodologies other than those based on "allylic chemistry" have been developed towards the preparation of stereodefined, highly substituted allylic amines. ${ }^{8}$ These synthetic approaches generally require the use of sensitive metal reagents, ${ }^{8 \mathrm{a}, 8 \mathrm{c}}$ stoichiometric amounts of additives, ${ }^{8 \mathrm{a}-\mathrm{d}, 8 \mathrm{f}}$ or the use of synthetically challenging, stereopredefined tri-substituted allylic surrogate precursors as starting materials. ${ }^{8 \mathrm{e}, 8 \mathrm{f}}$ These features adversely affect the accompanying waste profiles of such strategies and may limit their practical application and/or scaleup.

Scheme 1. Metal Catalyzed Allylic Chemistry for various Transformations.

(a)

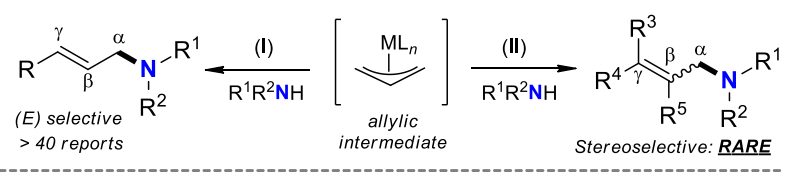

(b) Previous work:

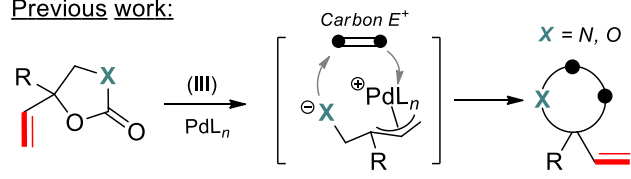

postulated

(c) This work:

$\stackrel{\text { This work: }}{\stackrel{(I V)}{\longrightarrow}}$
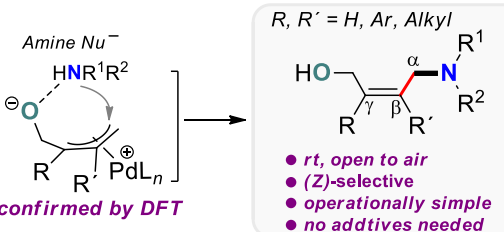
Therefore, the development of a general and practical methodology for the direct stereoselective synthesis of highly substituted allylic amines from modular and easy to prepare allylic surrogates remains a highly attractive though challenging target.

Ooi $^{9 \mathrm{a}}$ and Zhang ${ }^{9 \mathrm{~b}-\mathrm{c}}$ previously reported decarboxylative strategies towards the enantioselective formation of heterocyclic molecules through a (postulated) zwitterionic "Pd-allyl" type intermediate that is able to intercept electrophilic Michael acceptors (Scheme 1b, route III) following cyclization. Conversely, we envisioned that nucleophilic attack by amines on the allylic fragment in such intermediates ${ }^{10,11}$ could provide stereocontrolled $\gamma$-disubstituted allylic amines (Scheme 1c, route IV) by judiciously tuning the nature of the ligands $\mathrm{L}_{n}$, the metal precursor and the reaction conditions. Here we report on a new, highly practical and general method for the preparation of functional tri- and tetra-substituted allylic amines that is further characterized by a high level of stereo-control towards the $(Z)$ isomer. This chemistry can be operated under ambient conditions without the need for special precautions, and provides access to a wide range of complex allylic amine scaffolds.

Detailed computational analysis has provided a mechanistic rationale for the stereoselective formation of $(Z)$-configured allylic amines. The optimized catalytic system kinetically favors the $(Z)$ isomer through a lower energy transition state that results in the formation of a six-membered palladacycle with $\mathrm{Pd}-\mathrm{O}$ chelation. Taking into account the limited knowledge in the area of stereocontrolled preparation of highly substituted olefin scaffolds, we believe that the present work opens up new synthetic opportunities for the construction of highly functionalized allylic amine/olefin compounds.

\section{RESULTS AND DISCUSSION}

Stereoselective Synthesis of Allylic Amines. Inspired by previous research, ${ }^{9}$ we first set out to examine room temperature conversion of vinyl carbonate $\mathbf{A}$ and tested various metal (pre)catalysts in combination with triphenylphosphine (L1) under neat conditions (Table 1, entries 1-5). As expected, the control reaction (entry 6) in the absence of any catalyst gave no conversion. It was found that the use of either $\mathrm{Pd}(\mathrm{OAc})_{2}$ or the White catalyst ${ }^{12}$ gave promising results with moderate yields of up to $49 \%$ and excellent stereoselectivity of $Z: E>97: 3$ ( $c f$., entries 3 and 5). Though the White catalyst showed lower total conversion (entry 5: 85\%) compared to the use of $\mathrm{Pd}(\mathrm{OAc})_{2}$ (entry 3; conversion $>99 \%$ ), higher chemo-selectivity towards the allylic amine product was noted. Therefore, we decided to use the White catalyst for further optimization of the protocol. The addition of a polar solvent, especially DMF (entry 9) or $\mathrm{MeOH}$ (entry 10) significantly increased the yield of the targeted allylic amine product with some erosion of the stereoselectivity. Considering the poor reproducibility of the experimental results with $\mathrm{MeOH}$ as solvent, the combination of the White catalyst with DMF was chosen to further screen other (di)phosphine ligands L2-L6 (entries 12-19). No reaction occurred with the more sterically demanding tricyclohexylphosphine (entry 12) pointing to a crucial role of the ligand structure.

We were pleased to find that the best combination of allylic amine yield and high stereoselectivity towards the $(Z)$ isomer could be achieved using the White catalyst precursor, diphos- phine L5 (DPEPhos) and DMF as solvent under ambient conditions (entry 15) without the requirement of any additives. It worth noting that in these screening reactions we were unable to observe any formation of the branched allylic amine product. Further to this, no special precaution were required making the protocol thus highly attractive from a practical point of view.

Table 1. Screening Towards the Stereoselective Formation of Allylic Amines using Carbonate A and Aniline as Substrates. $^{\mathrm{a}}$

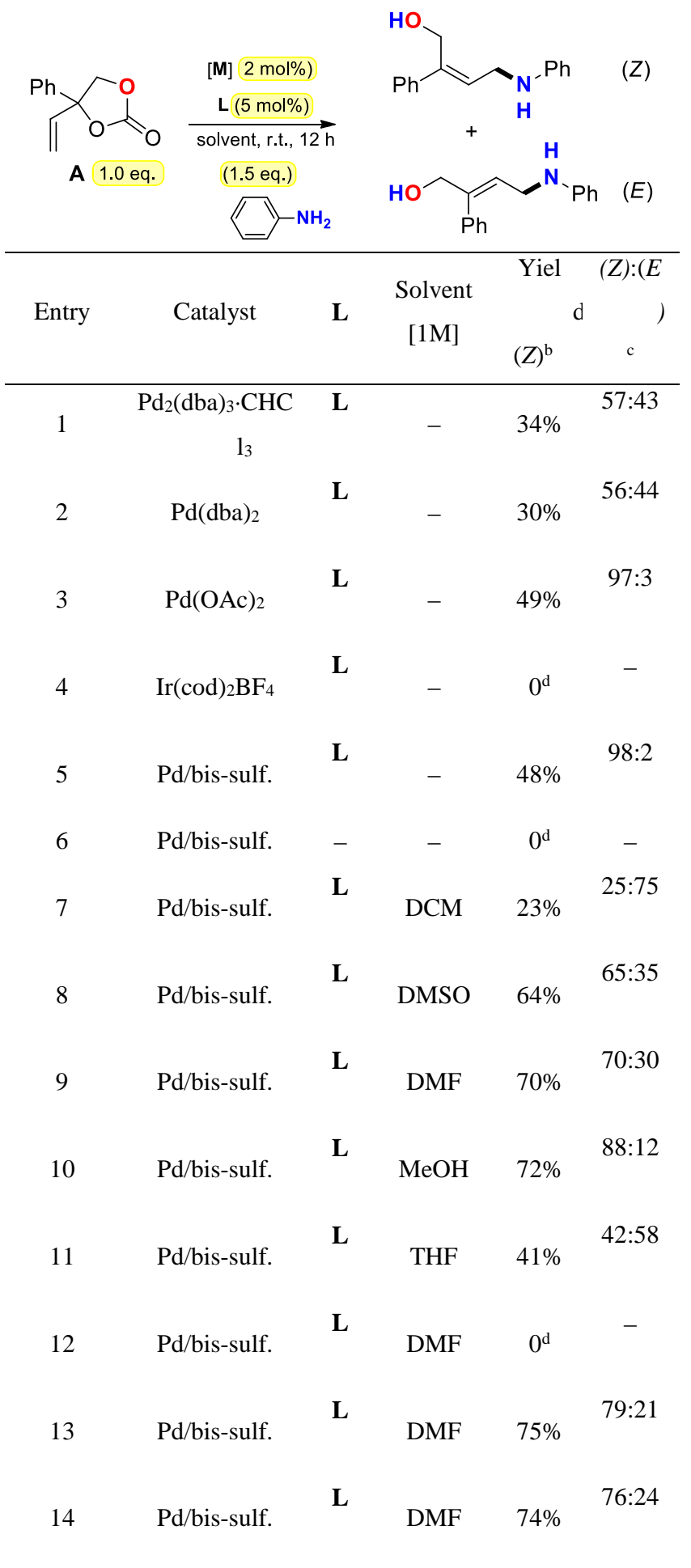




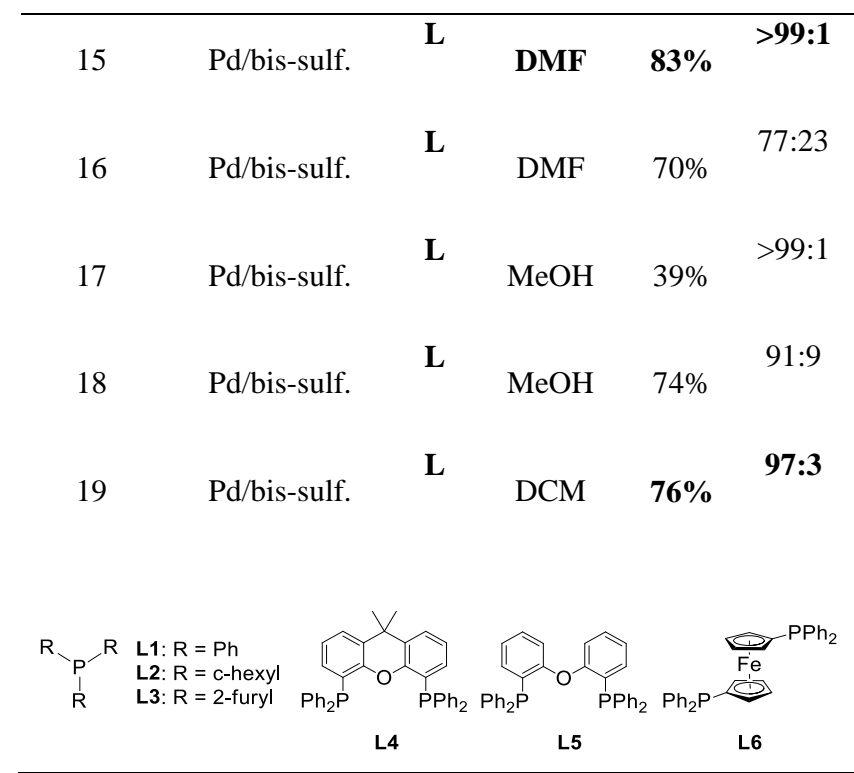

a Reaction conditions: $0.2 \mathrm{mmol}$ of carbonate, $0.3 \mathrm{mmol}$ of aniline, $0.2 \mathrm{~mL}$ of solvent where indicated, $\mathrm{rt}$; $\mathrm{Pd} / \mathrm{bis}$-sulf. refers to the White catalyst. ${ }^{\mathrm{b}}$ Refers to NMR yield using toluene as an internal standard. ${ }^{\mathrm{c}}$ Determined by ${ }^{1} \mathrm{H}$ NMR; ${ }^{\mathrm{d}}$ No reaction observed.

With the optimized conditions in hand, we turned our focus on exploring the generality of the approach (Figure 1) by first varying the amine substrate $(c f$., synthesis of allylic amines 1-16). Generally, the newly developed decarboxylative amination approach proceeded with excellent stereoselectivity with $Z / E$ ratios typically being $>99: 1$ and appreciable isolated yields when using aniline derivatives bearing either electron-withdrawing or -donating groups. The more deactivated anilines also showed significant reactivity ( $c f$., synthesis of $\mathbf{7 , 8}$ and $\mathbf{1 0})$. Various substituents in the aniline substrate including iodide (4), fluoro (5), methoxy (3), ester (8) and nitro (10) groups were tolerated. The protocol also endorsed the use of the ortho-substituted aniline (11), and other sterically demanding anilines as illustrated by the preparation of allylic amines 13-15: compound 13 represents an interesting scaffold with two distinct $\mathrm{N}$-allylic groups. The use of cyclohexyl amine as a reaction partner (16) also provided the $(Z)$ configured allylic amine though in moderate yield. ${ }^{13}$ These reactions can be easily scaled up as demonstrated for $\mathbf{1}$ (30 times) and $\mathbf{1 5}$ (15 times). Of further note is that the external base-free conditions of the optimized protocol further illustrates the mild and selective nature of these conversions. ${ }^{14}$
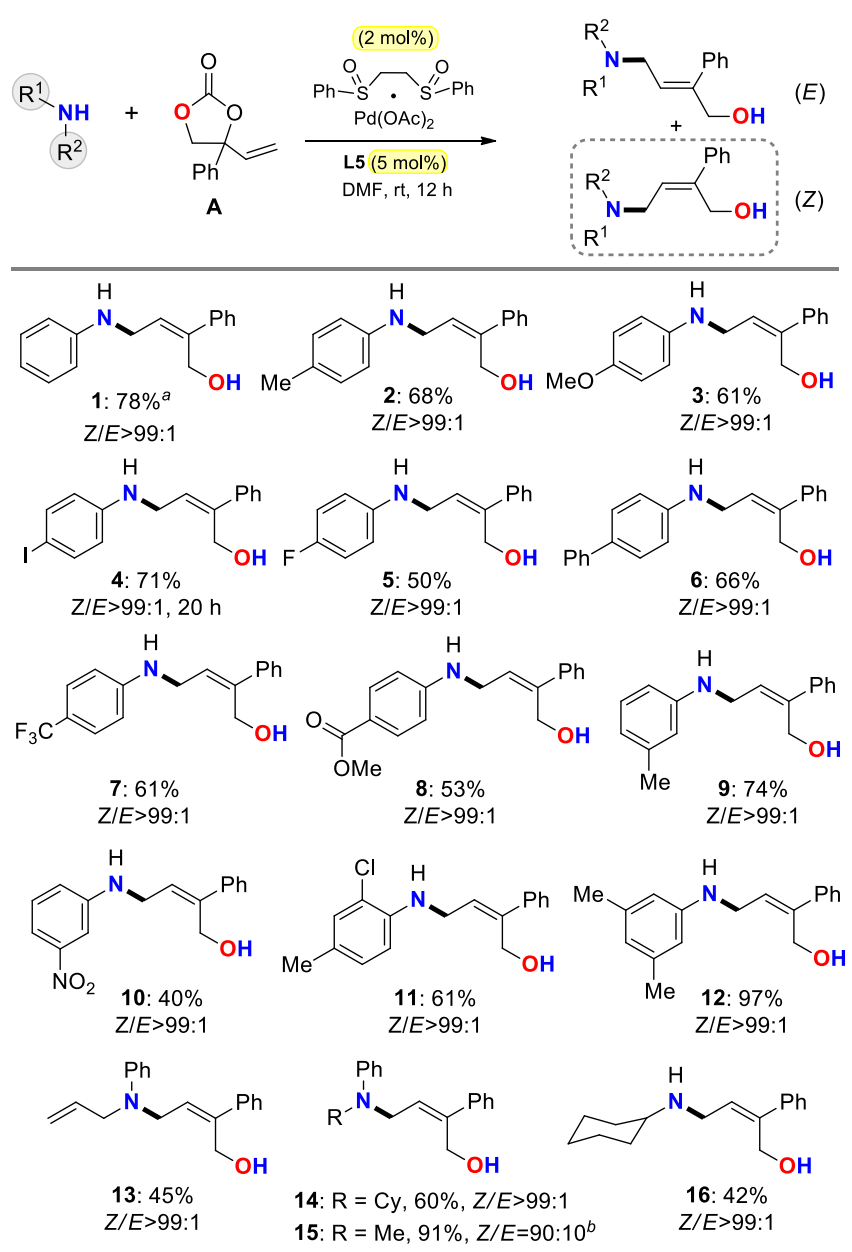

Figure 1. Scope in amine reaction partners: $0.2 \mathrm{mmol}$ carbonate $\mathbf{A}$ used unless stated otherwise, 1.5 eq. of amine, rt, $12 \mathrm{~h}$, open to air: No branched allylic amine formation could be observed. ${ }^{a} 6 \mathrm{mmol}$ scale. ${ }^{b} 3 \mathrm{mmol}$ scale. 


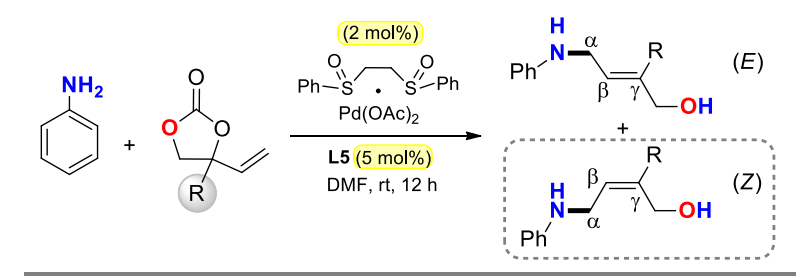<smiles>OC/C(=C\CNc1ccccc1)c1ccc(F)cc1</smiles><smiles>Cc1ccc(/C(=C/CNc2ccccc2)CO)cc1</smiles><smiles>OC/C(=C\CNc1ccccc1)c1ccccc1Br</smiles>
$18: 73 \%$
$Z I E>99: 1$

19: $67 \%$ $Z / E=90: 10$<smiles>COC(=O)c1ccc(/C(=C/CNc2ccccc2)CO)cc1</smiles><smiles>OC/C(=C\CNc1ccccc1)c1ccc(-c2ccccc2)cc1</smiles><smiles>OC/C(=C\CNc1ccccc1)c1cccc(Br)c1</smiles>

21: $41 \%$ $Z I E=90: 10$

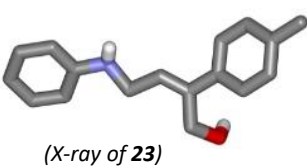

ZIE $>99: 1$<smiles>Cc1ccc(/C(=C/CNc2ccccc2)CO)cc1</smiles>

25: $56 \%$

$Z / E>99: 1$

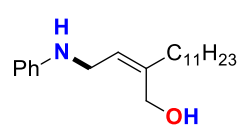

28: $47 \%, Z / E>99: 1$<smiles>OC/C(=C\CNc1ccccc1)c1ccco1</smiles>

26: $93 \%$ $E / Z>99: 1$<smiles>C=C/C(=C\CNc1ccccc1)CO</smiles>

29: $56 \%$

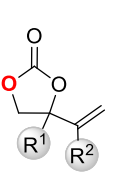

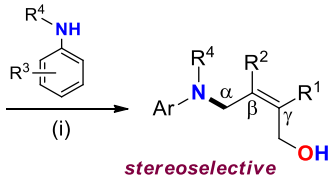
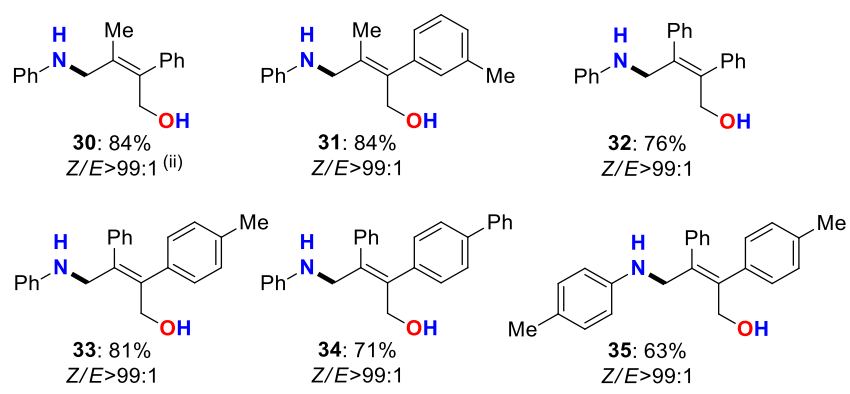<smiles>COc1ccc(NC/C(=C(/CO)c2ccc(-c3ccccc3)cc2)C(CO)c2ccc(-c3ccc(-c4ccccc4)cc3)cc2)cc1</smiles>

Figure 3. Preparation of tetra-substituted allylic amines 30-38. Conditions: (i) $0.2 \mathrm{mmol}$ of carbonate, 1.5 eq. of aniline, White catalyst (2.0 mol\%), L5 (5.0 $\mathrm{mol} \%$ ), DMF, $12 \mathrm{~h}, 70^{\circ} \mathrm{C}$, open to air; (ii) Reaction was carried out at rt. No branched allylic amine formation could be observed.

To scrutinize whether the stereoselective formation of the allylic amines is under thermodynamically control, we decided to prepare tetra-substituted allylic amines. Gratifyingly, the stereoselective preparation of tetra-substituted allylic amines 30-38 proved to be feasible (Figure 3: $Z / E>99: 1$; except for 36: $Z / E=$ 90:10). Whereas the reaction to prepare allylic amines 31-38 did not give any conversion at room temperature, increasing the reaction temperature to $70^{\circ} \mathrm{C}$ smoothly led to their formation in appreciable yields without affecting the stereoselective course of the reactions. The stereochemical configuration of these products was conveniently confirmed by 2D NMR techniques (see Supporting Information). figuration but its formation follows a similar stereocontrolled amination pathway as for the other reported compounds.

Subsequently, the carbonate partner was systematically varied (Figure 2) giving access to a wide range of highly functional allylic amines (17-29) in moderate to excellent yields with excellent stereocontrol in most of the cases with $Z / E$ ratios of $>90: 10$. Many different functionalities can be readily introduced in the $\gamma$-position including para-, meta-, and ortho-substituted aryls (17-23), furans (24 and 26) and thiophene (25) groups. The presence of ortho-substituents on the aryl group of the cyclic carbonate, however, lowers the stereo-control of the catalytic process (for 20: $Z / E=77: 23$ ), and also meta-substitution results in a small loss of stereo-induction (for 19: $Z / E=$ 90:10). The presence of a bulky naphthyl group did not affect the stereocontrol exerted in the catalytic protocol ( $c f$., formation of 27). The use of alkyl-substituted vinyl carbonates $(\mathrm{R}=\mathrm{alkyl})$ also selectively leads to the formation of $(Z)$ allylic amines $\mathbf{2 8}$ and 29. X-ray analyses carried out for allylic amines $\mathbf{2 3}$ and 29, apart from 1D/2D NMR studies, further supported the $(Z)$-configuration of the products.

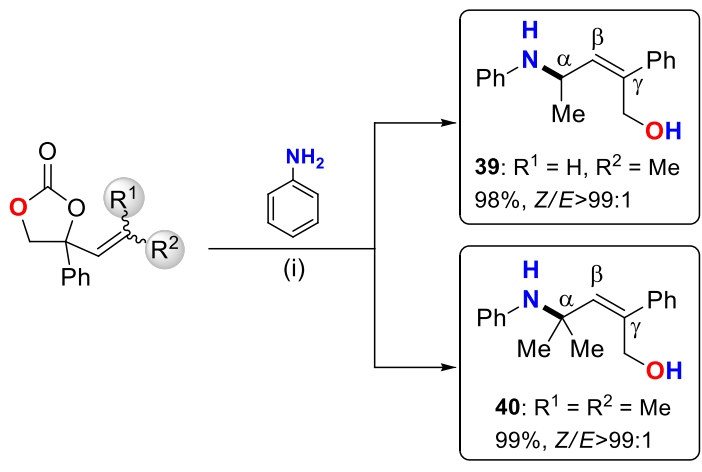

Figure 4. Formation of $\alpha$-functionalized allylic amines $\mathbf{3 9}$ and $\mathbf{4 0}$. Conditions: (i) $0.2 \mathrm{mmol}$ carbonate, $1.5 \mathrm{eq}$. of aniline, White catalyst $(2.0 \mathrm{~mol} \%)$, L5 (5.0 mol\%), DMF, $12 \mathrm{~h}$, rt, open to air.

The straightforward formation of 30-38 demonstrates the potential to install substituents on the $\beta$-carbon of the allylic scaffolds thus further amplifying the generality of the protocol. No- 
tably, the products 30, 31, and 33-38 contain four different substituents in the olefinic unit under exquisite stereocontrol, which is known to be highly challenging. ${ }^{1,15}$ There does not seem to be an obvious thermodynamical control in the reactions leading to allylic amines 32-38, a hypothesis that was confirmed by DFT calculations. Indeed, calculations for compounds $\mathbf{3 2}$ and $\mathbf{3 3}$ (see Supporting Information) showed the $\boldsymbol{E}$ isomers to be slightly more stable compared to the observed $\boldsymbol{Z}$ ones by 0.5 and $1.1 \mathrm{kcal} / \mathrm{mol}$, respectively. Therefore, the overall process is confirmed not to be under thermodynamic control. ${ }^{16}$

Remarkably, upon use of a stereoisomeric mixture of the cyclic carbonate precursor (Figure $4, \mathrm{R}^{1}=\mathrm{H}, \mathrm{R}^{2}=\mathrm{Me}$ ) ${ }^{17}$ virtually quantitative and stereoselective formation of $\alpha$-functionalized allylic amine (Z)-39 was achieved. This result suggests that stereopure vinyl-carbonate precursors are not a requisite for the formation $\alpha$-functionalized $(Z)$ allylic amines. Introduction of two substituents at the $\alpha$-position also proved to be feasible as illustrated by the synthesis of (Z)-40 (Figure 4) in $99 \%$ yield. In order to further expand the scope of our optimized catalytic system, highly substituted carbonates B (Figure 5) were prepared ${ }^{18}$ with the objective to prepare $\delta$-functionalized allylic amines $\mathbf{4 1}$ and 42. However their formation could not be observed at temperatures of up to $100^{\circ} \mathrm{C}$ with quantitative recovery of carbonates $\mathbf{B}$, pointing at some steric limitation of the present catalytic methodology.

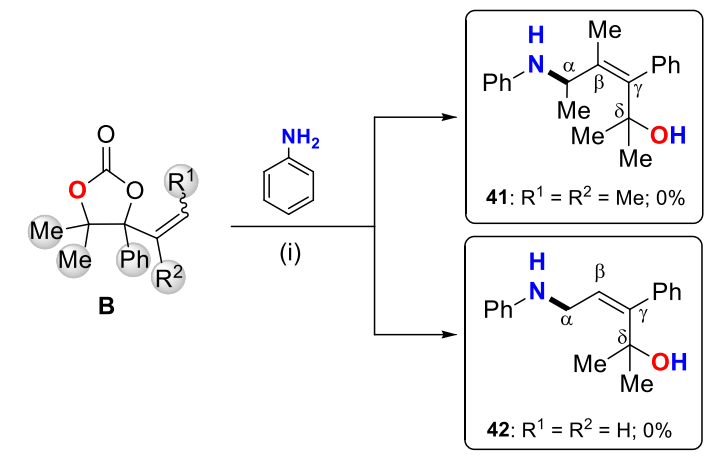

Figure 5. Attempted synthesis of $\delta$-functionalized allylic amines $\mathbf{4 1}$ and $\mathbf{4 2}$ from carbonate B. Conditions: (i) $0.2 \mathrm{mmol}$ carbonate, $1.5 \mathrm{eq}$. of aniline, White catalyst (2.0 mol\%), L5 (5.0 mol\%), DMF, $12 \mathrm{~h}, \mathrm{rt}-100^{\circ} \mathrm{C}$, open to air.

In order to further examine whether the high stereoselective nature of the allylic amine formation largely depends on the substituents of the vinyl carbonate substrate and whether the process is under thermodynamic control ( $c f$., the $\mathrm{R}$ group in Figure 2), commercially available and minimally substituted vinyl carbonate $\mathbf{C}$ was selected and treated with six different amine nucleophiles (Figure 6). As can be judged from the results, in the presence of sterically less demanding anilines (Figure 6, cf. 43-45), the nucleophilic attack on the internal carbon is favored leading to the branched allylic amines as the major products. However, such branched products were never observed in the preparation of compounds 1-40. By further increasing the bulkiness of the aniline nucleophile, the $\gamma$-mono-substituted $(Z)$ configured $^{19}$ allylic amines 46-48 were isolated as major component in moderate/good yields under high stereocontrol $(Z: E \geq$ 4:1). These experiments further support that these stereoselective transformations are not under strict thermodynamic control.
The combined results exclude that the substrate itself largely controls the stereo-chemical nature of the allylic amine formation, and that the catalyst (in situ formed from the White precursor and L5) combined with the medium (DMF) are essential for high stereo-induction in these transformations.
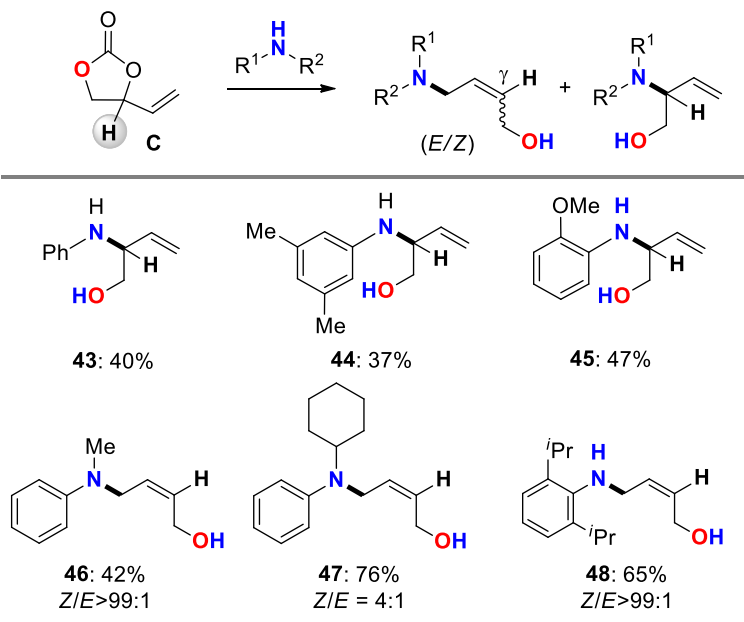

Figure 6. Preparation of allylic amines $\mathbf{4 3 - 4 8}$ from carbonate $\mathbf{C}$ using different amine nucleophiles. Conditions: (i) $0.2 \mathrm{mmol}$ carbonate, $1.5 \mathrm{eq}$. of aniline derivative, White catalyst (2.0 mol\%), L5 (5.0 mol\%), DMF, $12 \mathrm{~h}$, rt, open to air.

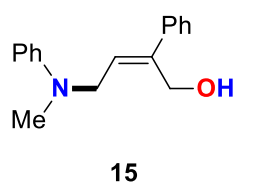

$(Z / E=90: 10)$

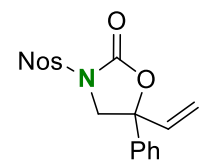

D
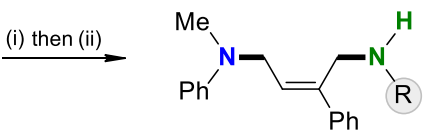

49: $\mathrm{R}=\mathrm{Ph}, 57 \%, \mathrm{Z} / E>99: 1$ 50: $\mathrm{R}=\mathrm{Bn}, 56 \%, \mathrm{Z} / E>99: 1$

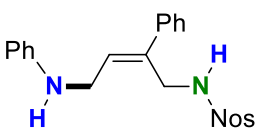

51: $86 \%, Z / E>99: 1$
Figure 7. Conversion of allylic amine 15 into (Z)-but-2-ene-1,4-diamines 49 and $\mathbf{5 0}$ and direct formation of diamine $\mathbf{5 1}$ from a cyclic carbamate precursor. Conditions: (i) $\mathrm{TsCl}, \mathrm{Et}_{2} \mathrm{O}, \mathrm{KOH}$; (ii) $\mathrm{RNH}_{2}, \mathrm{~K}_{2} \mathrm{CO}_{3}, \mathrm{DMF}$; (iii) Conditions: 0.2 mmol carbamate, 1.5 eq. of aniline, White catalyst (2.0 mol\%), L5 (5.0 mol\%), DMF, $12 \mathrm{~h}$, rt, open to air. Nos = 2-nitrobenzenesulfonyl.

Highly functionalized allylic amine and/or olefin scaffolds have been found as various building blocks/reaction partners. ${ }^{1,20}$ The formal ( $Z$ )-1,4-amino-alcohols reported herein also serve as reaction partners towards the synthesis of a wide variety of 1,4-diamines. Such compounds are of potential biological interest but are typically more difficult to prepare stereoselectively than vicinal diamines. ${ }^{21}$ The pendent hydroxyl groups present in these newly prepared allylic amines allow an easy entry to unsaturated, nonsymmetrical 1,4-diamine scaffolds as illustrated by the synthesis of (Z)-but-2-ene-1,4-diamines 49 and $\mathbf{5 0}$ (Figure 7) using standard nucleophilic displacements. This procedure thus allows for pre-selection of functional aryl and/or alkyl substituents on the nitrogen centers (useful towards post-modification) by the appropriate choice of the amine reagent during 
the formation of the allylic amine, and subsequent use of another amine reagent in the nucleophilic substitution reaction. More directly, $(Z)$-configured diamines can also be prepared by using cyclic carbamate D (Figure 7) that upon treatment with aniline under the optimized conditions provided an easy entry towards diamine $\mathbf{5 1}(86 \%)$ in excellent stereoselectivity.

Mechanistic Investigations. Intrigued by the high level of stereochemical control in the formation of the allylic amine products, we decided to investigate the reaction mechanism by computational methods. Computational approaches have been indeed successful in mechanistic studies on palladium chemistry, ${ }^{22}$ selectivity ${ }^{23}$ and in processes involving carbon dioxide. ${ }^{24,25}$ For our calculations, we chose the system comprising of the catalyst derived from the White precursor and DPEPhos (L5), aniline and the dimethyl substituted cyclic carbonate reported in Figure 4 leading to allylic amine product 40, since these conditions gave quantitative and exclusive formation of the $(Z)$-configured allylic amine. As such it was considered an ideal case for the computational studies that focused on providing fundamental insight into the stereoselective nature of this catalytic process. The results reported in what follows correspond to geometry optimizations with the B97D functional in DMF solvent followed by single point calculations with a SDD basis set for Pd and 6-311++g(d,p) for all other atoms. All reported energies are free energies in solution. ${ }^{26}$ The computed reaction mechanism is visualized in Scheme 2, and a detailed energy profile is shown in Figure 8. The computed species are labeled with the prefix $\mathbf{t}$ (for "theoretical") to avoid confusion with the numbered experimental products discussed above.

Scheme 2. Computed Overall Mechanism for the Formation of Allylic Amine (40).

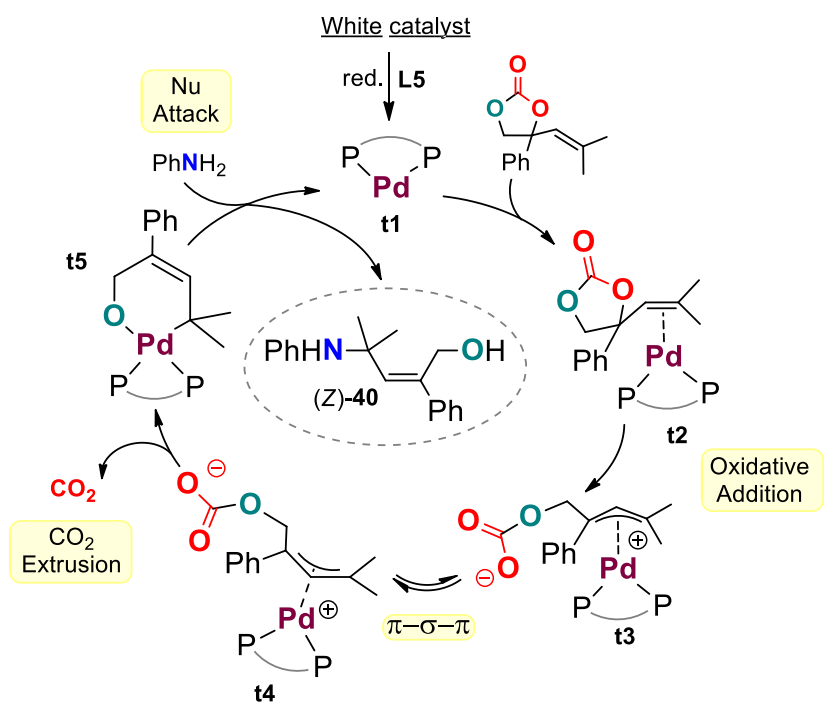

The main features of the mechanism are shown in the simplified Scheme 2. The initial steps of the reaction are the expected, i.e. the reduced form of the White catalyst $\mathbf{t} 1$ coordinates the vinyl double bond to yield intermediate $\mathbf{t} 2$. Then an oxidative cleavage of the cyclic carbonate takes place. There is a formal transfer of two electrons from the Pd center to the 


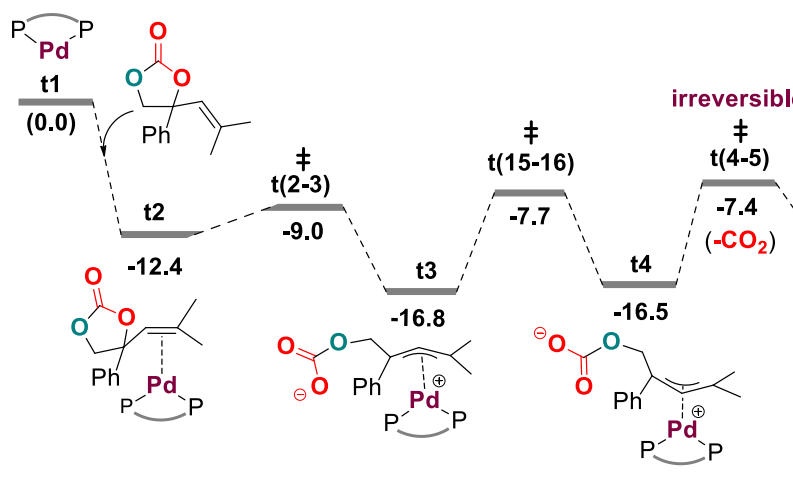

syn/anti isomerism

\section{(Z)-pathway}

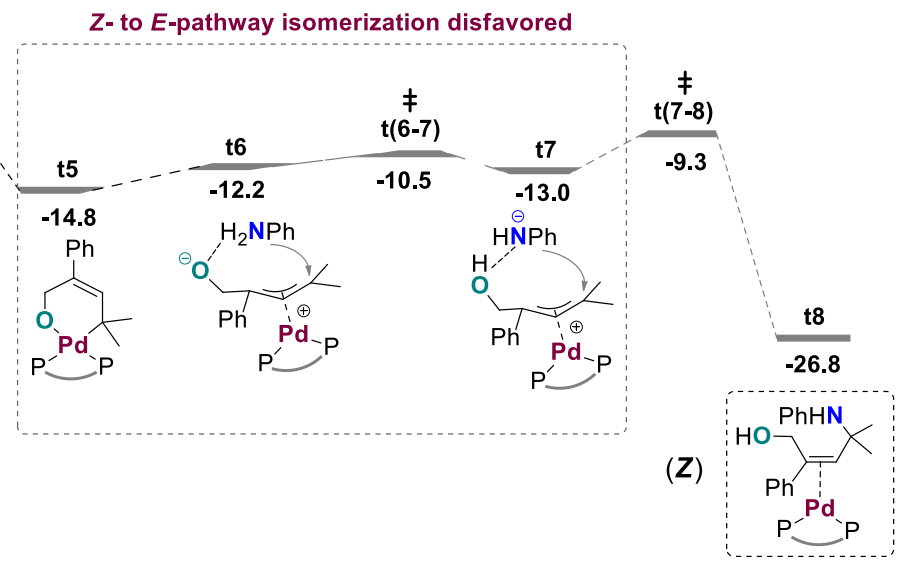

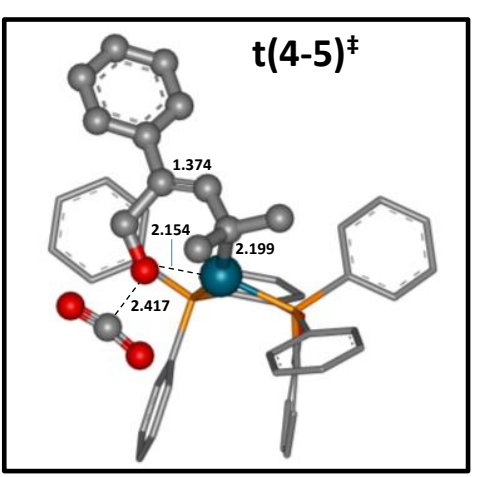

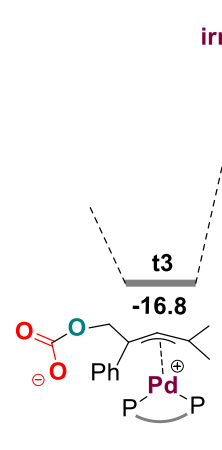

\section{(E)-pathway}

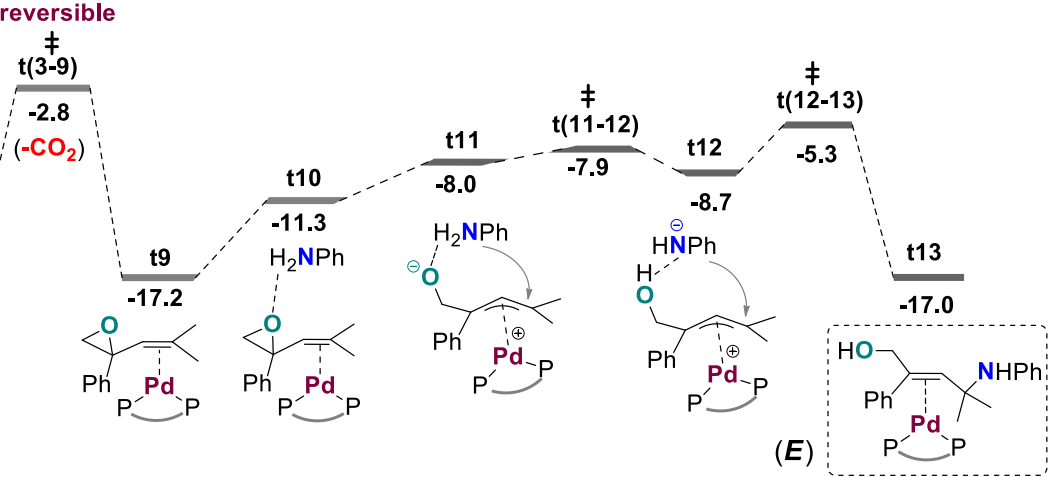

Figure 8. Computed free energy profile (in $\mathrm{kcal} / \mathrm{mol}$ ) for the synthesis of allylic amine product $\mathbf{4 0}$ reported in Figure 4 . The structure of the transition state leading to t5 (i.e., $\mathbf{t}\left(\mathbf{4 - 5 ) ^ { \ddagger } )}\right.$ is shown in the inset with selected calculated bond lengths.

organic substrate, and the resulting intermediate $\mathbf{t} 3$ contains an $\eta^{3}$ allylic group attached to an open carbonate. Up to this intermediate $\mathbf{t} 3$, our calculations closely follow previous mechanistic postulations on related processes. ${ }^{9}$ Isomerization of $\mathbf{t} 3$ through a $\pi-\sigma-\pi$ interconversion process leads to intermediate t4. It is worth noting that at this stage it is far from obvious how stereoselectivity can be achieved from this open chain species. Intermediate $\mathbf{t} \mathbf{4}$ contains an allylic group arranged in a way leading to the $(Z)$-configuration in the final product. The key to the stereoselectivity is in the continuation of the process: the extrusion of the carbon dioxide molecule results in the formation of intermediate t5 containing a six-membered palladacyclic ring. The arrangement of the substituents in intermediate $\mathbf{t 5}$ is such that subsequent nucleophilic attack by the aniline results in the release of the product molecule $\mathbf{4 0}$ and recovery of the catalyst $\mathbf{t} \mathbf{1}$. The formation of intermediate $\mathbf{t 5}$ is thus key to the overall selectivity of the process.

A more detailed description of the reaction mechanism is presented in the free energy profiles in Figure $8((\mathbf{Z})$ and $(\mathbf{E})$ pathways). Due to the irreversible $\mathrm{CO}_{2}$ extrusion step, the key kinetic barriers that determine the stereochemical course of the reaction are $\mathbf{t}(\mathbf{4 - 5})^{*}$ for the conversion of $\mathbf{t} 4 \rightarrow \mathbf{t 5}$ in the $(Z)$ pathway, and $\mathbf{t}(\mathbf{3 - 9})^{*}$ for the conversion of $\mathbf{t 3} \rightarrow \mathbf{t} \mathbf{9}$ in the (E) pathway. In the $(\mathbf{Z})$ pathway this barrier is $4.6 \mathrm{kcal} / \mathrm{mol}$ lower in energy, and therefore the formation of $(Z)$ allylic amine $\mathbf{4 0}$ at $\mathrm{rt}$ is favored. ${ }^{27}$ Unlike the six-membered palladacycle $\mathbf{t 5}$ in the $(\mathbf{Z})$ pathway, in the (E) pathway an epoxide intermediate $\mathbf{t} 9$ is formed and evolves into the $(E)$-configured product $\mathbf{t 1 3}$. The formation of the palladacyclic intermediate $\mathbf{t 5}$ is preceded by $\mathbf{t}(4-5)^{*}$ and the structure of this TS is shown in the inset of Figure 8 . The structural features of $\mathbf{t}(\mathbf{4 - 5})^{\ddagger}$ emphasize the importance of $\mathrm{Pd}-\mathrm{O}$ chelation (its calculated bond length is 2.154 $\AA$ ) to reduce the energy barrier and plays a key role towards the kinetic differentiation between both pathways leading to the $(Z)$ and $(E)$ product, respectively. This $\mathrm{Pd}-\mathrm{O}$ chelation is not feasible going through $\mathbf{t}(\mathbf{3 - 9})^{\ddagger}$ of the (E) pathway, see Supporting Information for details (Figure S1).

The profile of the $(\mathbf{Z})$ pathway in Figure 8 shows some subtleties in the last part of the reaction, i.e., the nucleophilic attack of the aniline on the catalyst-substrate complex. The aniline makes a hydrogen bond to the anionic oxygen center of $\mathbf{t 5}$ resulting in intermediate t6 which rearranges through proton transfer to intermediate $\mathbf{t} 7$. From $\mathbf{t 6}$ to the final product $\mathbf{t} \mathbf{8}$ there are two possible routes. The preferred one is stepwise, with first formation of an $\mathrm{O}-\mathrm{H}$ bond in intermediate $\mathbf{t} 7$ followed by a nucleophilic attack of an amide nucleophile through $\mathbf{t}(\mathbf{7 - 8})^{\ddagger}$. The concerted option has a higher transition state, $\mathbf{t}(\mathbf{6 - 8})^{*}$ at -6.0 $\mathrm{kcal} / \mathrm{mol}$, and is $3.3 \mathrm{kcal} / \mathrm{mol}$ above $\mathbf{t}(\mathbf{7 - 8})^{*}$ and must thus be discarded (Supporting Information; Figure S2). ${ }^{28}$ The calcu- 
lated formation of a branched allylic amine $\mathbf{t 8}^{\prime}$ from intermediate $\mathbf{t} 7$ shows a transition state $\mathbf{t}\left(\mathbf{7 - 8}^{\prime}\right)^{\ddagger}$ with a barrier at -0.6 $\mathrm{kcal} / \mathrm{mol}$ which is much higher in energy than the one $(-9.3$ $\mathrm{kcal} / \mathrm{mol}$ ) computed for $\mathbf{t}(\mathbf{7 - 8})^{\ddagger}$. Therefore the experimental observation of only linear allylic amine formation for 1-40 corroborates with this computational analysis (Supporting Information; Figure S3).

Other considerations are also important to discuss here which relate to the possibility of syn/anti isomerization ${ }^{29}$ of the allyl-Pd species. First the isomerization between $\mathbf{t} 3$ and $\mathbf{t} \mathbf{4}$ was examined in more detail (Figure 9) through $\pi-\sigma-\pi$ interconversion. ${ }^{30}$ The highest point in this isomerization process, $\mathbf{t}(\mathbf{1 5}$ 16) ${ }^{\ddagger}$, has an energy of $-7.7 \mathrm{kcal} / \mathrm{mol}$, slightly below that calculated for $\mathbf{t}(\mathbf{4 - 5})^{*}$ in the formation of the $(Z)$ allylic amine 40 , and substantially below the value of $\mathbf{t}(\mathbf{3 - 9})$ in the formation of the (E) allylic amine. Thus, this means that syn/anti interconversion before $\mathrm{CO}_{2}$ extrusion is kinetically feasible. More relevant towards a detailed understanding of the high stereoselectivity in these allylic amine formation reactions is the possible isomerizations $(\mathbf{t 5} \rightarrow \mathbf{t 9}),(\mathbf{t 6} \rightarrow \mathbf{t 1 1})$ and $(\mathbf{t 7} \rightarrow \mathbf{t 1 2})$ that takes place after $\mathrm{CO}_{2}$ elimination (see Figure 10 and Figures $\mathrm{S} 4$ and S5). The formation of $\mathbf{t 1 2}$ from $\mathbf{t} \mathbf{7}$ also involves a $\pi-\sigma-\pi$ interconversion process. As can be judged from Figures 8 and 10, the intermediate with the highest energy $(\mathbf{t} 26$; at $-3.2 \mathrm{kcal} / \mathrm{mol})$ is significantly higher than the highest transition state (after $\mathrm{CO}_{2}$ extrusion) of the pathway leading to $(Z)$-allylic amine 40 with a $\mathbf{t}(7-$ 8) at $-9.3 \mathrm{kcal} / \mathrm{mol}$.

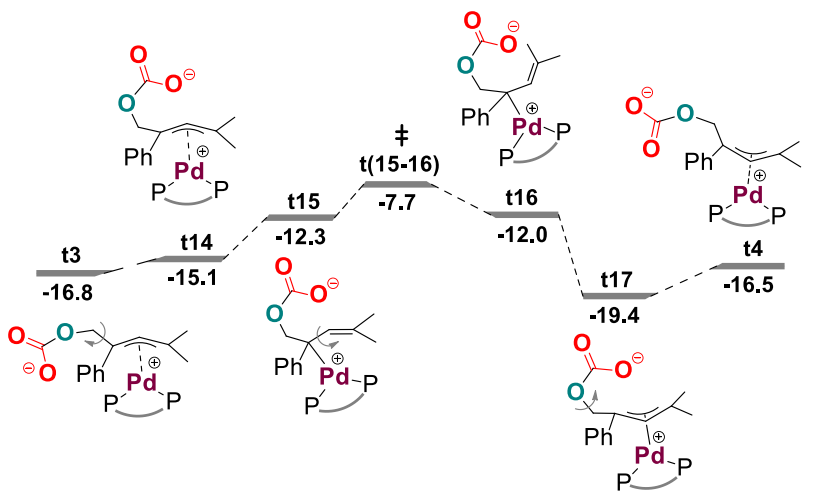

Figure 9. Energy profile of syn/anti isomerization process from $\mathbf{t 3} \rightarrow \mathbf{t} \mathbf{4}$ through $\pi-\sigma-\pi$ interconversion.

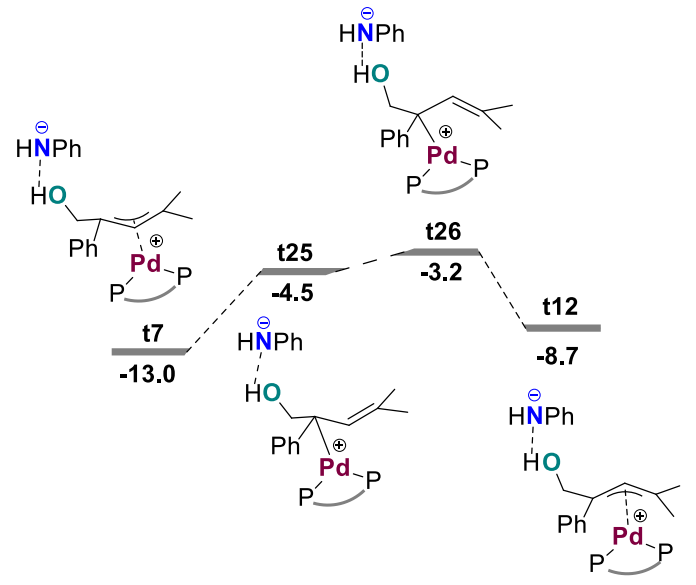

Figure 10. Energy profile of syn/anti isomerization process from $\mathbf{t 7} \rightarrow \mathbf{t 1 2}$ through $\pi-\sigma-\pi$ interconversion.
For the other possible isomerizations $\mathbf{t 5} \rightarrow \mathbf{t} \mathbf{9}$ and $\mathbf{t 6} \rightarrow \mathbf{t 1 1}$ similar/larger differences between the highest energies of the involved intermediates $(\mathbf{t} 20$ at $-0.7 \mathrm{kcal} / \mathrm{mol}$, and $\mathbf{t} 24$ at -3.0 $\mathrm{kcal} / \mathrm{mol}$; see Figure S4 and S5 in Supporting Information) were calculated. Thus, with an additional energy requirement of at least $6.1 \mathrm{kcal} / \mathrm{mol}$, these isomerization reactions beyond selectivity determining $\mathbf{t}(\mathbf{4 - 5})^{\ddagger}$ are clearly disfavored under the experimental conditions.

One of the key points of the mechanism is thus that syn-anti isomerization before decarboxylation is facile, but is relatively slow after decarboxylation. It seems to be intrinsically more facile going from a $\eta^{3}$ to $\eta^{1}$ coordination before decarboxylation (i.e., from $\mathbf{t} 3$ to $\mathbf{t 1 5} ; 4.5 \mathrm{kcal} / \mathrm{mol}$ uphill, Figure 9). This isomerization feature is not as facile after decarboxylation going from $\mathbf{t} 7$ to $\mathbf{t} 25(8.5 \mathrm{kcal} / \mathrm{mol}$ uphill, Figure 10$)$. This is likely associated to the superior electron-delocalization capability of the carbonate group with respect to the $\mathrm{Ph}-\mathrm{NH} \cdots \mathrm{OH}$-fragment present after decarboxylation. This hypothesis is further supported by the other computed $\pi-\sigma$ interconversion steps $\mathbf{t 1 9} \rightarrow \mathbf{t} 20(9.2 \mathrm{kcal} / \mathrm{mol}$ uphill $)$ and $\mathbf{t 6} \rightarrow \mathbf{t} 23(7.6 \mathrm{kcal} / \mathrm{mol} \mathrm{up}-$ hill), see Supporting Information. The latter $\pi-\sigma$ interconversions thus also require significantly higher energies than noted for $\mathbf{t 3} \rightarrow \mathbf{t 1 5}$ occurring before $\mathrm{CO}_{2}$ extrusion.

Overall, the computed mechanism is in line with several experimental observations. The initial coordination of the vinyl group to the palladium species $\mathbf{t} 1$ shows some steric restraints. In this respect, the deterioration of the stereo-selectivity upon changing the aryl substitution from "para" to "meta" or "ortho" in the cyclic carbonate precursor ( $c f$., formation of 18-20, Figure 2), and the lack of reactivity for the sterically crowded carbonate substrates B (Figure 5) can be justified. For the $(Z)$ allylic amines 1-40 we did not detect branched products in accord with the computational results. The observation of branched allylic amine formation when using non-substituted vinyl carbonate $\mathbf{C}$ as starting material (Figure 6) suggested a different intrinsic reactivity of non-substituted versus substituted vinyl carbonates ( $c f$., Figure 1-4). ${ }^{31}$ The fact that a stereoisomeric mixture of a vinyl carbonate converges to the allylic amine $(Z)$ 39 supports isomerization of the Pd-allyl intermediate before $\mathrm{CO}_{2}$ extrusion.

\section{CONCLUSION}

In summary, the new methodology presented herein delivers a general, practical and mild route for the stereoselective formation of highly substituted $(Z)$-configured allylic amine compounds. Further to this, results presented herein demonstrate wide scope in reaction partners allowing for the easy introduction of substituents in the $\alpha$-, $\beta$ - and $\gamma$-position of the alyllic unit. Most of these $(Z)$-configured allylic amines can be prepared under ambient conditions with $\mathrm{CO}_{2}$ as the sole waste, avoiding special precautions with respect to air/moisture sensitivity. This protocol does not require any additive while displaying wide scope in functional groups and substitution patterns. Further to this, the starting materials (cyclic vinyl carbonates and amines) are readily accessible and modular enabling the construction of pre-designed allylic amine scaffolds. The synthetic utility of these allylic amines was demonstrated as exemplified by the synthesis of (Z)-but-2-ene-1,4-diamines potentially useful in biological applications. 
Importantly, DFT calculations have revealed the rationale of the excellent stereocontrol in these transformations and the transition state $\mathbf{t}(\mathbf{4 - 5})^{\ddagger}$, with a lower barrier, leading to a $(Z)$-configured six-membered palladacycle $\mathbf{t 5}$ was computed as a crucial intermediate towards a kinetic differentiation between the pathways leading to either the $(E)$ or $(Z)$ product, with $\mathrm{Pd}-\mathrm{O}$ chelation as a stabilizing structural feature. This latter feature guides the process towards the formation of a $(Z)$-configured allylic amine. The DFT studies reported here add crucial information with respect to the mechanistic understanding in decarboxylative functionalization of vinyl carbonates, and differentiates from a previously postulated zwitterionic species. ${ }^{9}$ This new mode of stereocontrol provides further synthetic potential for the functionalization of allylic surrogates, giving prospectively access to various types of stereopure and functionalized olefin building blocks being of general synthetic interest.

\section{ASSOCIATED CONTENT}

Supporting Information. Experimental details for the carbonate substrate synthesis, copies of relevant NMR and IR spectra of all allylic amine products, X-ray data in cif format, computational details, summary of alternative computed mechanisms and Cartesian coordinates of all optimized structures. This material is available free of charge via the Internet at http://pubs.acs.org. A dataset collection of computational results is available in the iochem-db database. $^{32}$

\section{AUTHOR INFORMATION}

\section{Corresponding Author}

*akleij@iciq.es; fmaseras@iciq.es

\section{Notes}

The authors declare no competing financial interest.

\section{ACKNOWLEDGEMENTS}

We thank ICIQ, ICREA, and the Spanish Ministerio de Economía y Competitividad (MINECO) through projects CTQ-2014-57661R and CTQ-2014-60419-R, and the Severo Ochoa Excellence Accreditation 2014-2018 through project SEV-2013-0319. FM and AWK also acknowledge support from RedINTECAT (CTQ201452974-REDC). Dr. Noemí Cabello, Sofía Arnal, and Vanessa Martínez are acknowledged for the mass analyses. WG thanks the Cellex foundation for funding of a postdoctoral fellowship. We sincerely thank Dr. Alexandr Shafir for useful discussions.

\section{- REFERENCES}

(1) Flynn, A. B.; Ogilvie, W. W. Chem. Rev. 2007, 107, 4698-4745.

(2) For the application of allylic amines in synthesis, please refer to: (a) Trost, B. M.; Crawley, M. L. Chem. Rev. 2003, 103, 2921-2943. (b) Johannsen, M.; Jørgensen, K. A. Chem. Rev. 1998, 98, 1689-1708. (c) Trost, B. M.; Van Vranken, D. L. Chem. Rev. 1996, 96, 395-422. (d) Huang, L.; Arndt, M.; Gooßen, K.; Heydt, H.; Gooßen, L. J. Chem. Rev. 2015, 115, 2596-2697. (e) Müller, T. E.; Beller, M. Chem. Rev. 1998, 98, 675-704. (f) Hong, S.; Marks, T. J. Acc. Chem. Res. 2004, 37, 673-686. (g) Müller, T. E.; Hultzsch, K. C.; Yus, M.; Foubelo, F.; Tada, M. Chem. Rev. 2008, 108, 3795-3892.

(3) See for reviews: (a) Butt, N. A.; Zhang, W. Chem. Soc. Rev. 2015, 44, 7929-7967. (b) Arnold, J. S.; Zhang, Q.; Nguyen, H. M. Eur. J. Org. Chem. 2014, 4925-4948. (c) Trost, B. M.; Zhang, T.; Sieber, J. D. Chem. Sci. 2010, 1, 427-440. See for representative contributions using allylic linear carbonates: (d) Leitner, A.; Shu, C.; Hartwig, J. F.
Org. Lett. 2005, 7, 1093-1096. (e) Moreno-Mañas, M.; Morral, L.; Pleixats, R. J. Org. Chem. 1998, 63, 6160-6166. (f) Leitner, A.; Shekhar, S.; Pouy, M. J.; Hartwig, J. F. J. Am. Chem. Soc. 2005, 127, 1550615514. (g) Shekhar, S.; Trantow, B.; Leitner, A.; Hartwig, J. F. J. Am. Chem. Soc. 2006, 128, 11770-11771. (h) Plietker, B. Angew. Chem. Int. Ed. 2006, 45, 6053-6056; For direct use of allylic alcohols: (i) Das, K.; Shibuya, R.; Nakahara, Y.; Germain, N.; Ohshima, T.; Mashima, K. Angew. Chem. Int. Ed. 2012, 51, 150-154. (j) Gumrukcu, Y.; de Bruin, B.; Reek, J. N. H. ChemSusChem 2014, 7, 890-896. (k) Yang, S.-C.; Tsai, Y.-C. Organometallics 2001, 20, 763-770. (1) Kinoshita, H.; Shinokubo, H.; Oshima, K. Org. Lett. 2004, 6, 4085-4088. (m) Ghosh, R.; Sarkar, A. J. Org. Chem. 2011, 76, 8508-8512. (n) Ohshima, T.; Miyamoto, Y.; Ipposhi, J.; Nakahara, Y.; Utsunomiya, M.; Mashima, K. J. Am. Chem. Soc. 2009, 131, 14317-14328. Miscellaneous examples: (o) Pace, V.; Martínez, F.; Fernádez, M.; Sinisterra, J. V.; Alcántara, A. R. Org. Lett. 2007, 9, 2661-2664. (p) Dubovyk, I.; Watson, I. D. G.; Yudin, A. K. J. Org. Chem. 2013, 78, 1559-1575. (q) Adak, L.; Chattopadhyay, K.; Ranu, B. C. J. Org. Chem. 2009, 74, 3982-3985.

(4) See for representative examples: (a) Banerjee, D.; Junge, K.; Beller, M. Angew. Chem. Int. Ed. 2014, 53, 1630-1635. (b) Banerjee, D.; Junge, K.; Beller, M. Org. Chem. Front. 2014, 1, 368-372. (c) Yi, C. S.; Yun, S. Y. Org. Lett. 2005, 7, 2181-2183. (d) Minami, T.; Okamoto, H.; Ikeda, S.; Tanaka, R.; Ozawa, F.; Yoshifuji, M. Angew. Chem. Int. Ed. 2001, 40, 4501-4503. (e) Qin, H.; Yamagiwa, N.; Matsunaga, S.; Shibasaki, M. J. Am. Chem. Soc. 2006, 128, 1611-1614.

(5) This methodology generally requires stoichiometric amounts of external oxidant: (a) Reed, S. A.; White, M. C. J. Am. Chem. Soc. 2008 130, 3316-3318. (b) Yin, G.; Wu, Y.; Liu, G. J. Am. Chem. Soc. 2010, 132, 11978-11987. (c) Sharma, A.; Hartwig, J. F. J. Am. Chem. Soc. 2013, 135, 17983-17989. (d) Paradine, S. M.; Griffin, J. R.; Zhao, J.; Petronico, A. L.; Miller, S. M.; White, M. C. Nat. Chem. 2015, 7, $987-$ 994. (e) C. C. Pattillo, I. I. Strambeanu, P. Calleja, N. A. Vermeulen, T. Mizuno, M. C. White, J. Am. Chem. Soc. 2016, 138, 1265-1272.

(6) Formation of $\gamma$-disubstituted allylic amines with two different substituents has been seldom achieved and only with poor stereo-selectivities and quite limited scope. Examples through diamination of dienes: (a) Martínez, C.; Martínez, L.; Kirsch, J.; Escudero-Adán, E. C.; Martin, E.; Muñiz, K. Eur. J. Org. Chem. 2014, 2017-2021. (b) Lishchynskyi, A.; Muñiz, K. Chem. Eur. J. 2012, 18, 2212-2216. Also see ref. $4 \mathrm{a}$ and $4 \mathrm{~b}$. Through allylic substitution reactions, see reference $3 \mathrm{~m}$.

(7) (a) Hikawa, H.; Yokoyama, Y. Org. Biomol. Chem. 2011, 9, 4044-4050. (b) Yokoyama, Y.; Takagi, N.; Hikawa, H.; Kaneko, S.; Tsubaki, N.; Okuno, H. Adv. Synth. Catal. 2007, 349, 662-668. (c) Ramanathan, B.; Odom, A. L. J. Am. Chem. Soc. 2006, 128, 9344-9345. (d) Zeng, X.; Soleilhavoup, M.; Bertrand, G. Org. Lett. 2009, 11, 31663169. Similar approaches have also been used in the synthesis of other alkene scaffolds, see for example: (e) Trost, B. M.; Malhotra, S.; Chan, W. H. J. Am. Chem. Soc. 2011, 133, 7328-7331. (f) Fang, X.; Li, H.; Jackstell, R.; Beller, M. J. Am. Chem. Soc. 2014, 136, 16039-16043.

(8) (a) Hussain, N.; Hussain, M. M.; Ziauddin, M.; Triyawatanyu, P.; Walsh, P. J. Org. Lett. 2011, 13, 6464-6467. (b) Tonogaki, K.; Itami, K.; Yoshida, J. J. Am. Chem. Soc. 2006, 128, 1464-1465. (c) Xie, M.; Sun, Y.; Zhang, W.; Gu, X.; Zhao, X.; Xie, F.; Wang, S. Synth. Commun. 2008, 38, 3785-3796. (d) Patel, S. J.; Jamison, T. F. Angew. Chem. Int. Ed. 2004, 43, 3941-3944. (e) By non-catalytic allylic substitutions: Sen, S. E.; Roach, S. L. Synthesis, 1995, 7, 756-758. (f) Anumandla, D.; Littlefield, R.; Jeffrey, C. S. Org. Lett. 2014, 16, 5112-5115.

(9) (a) Ohmatsu, K.; Imagawa, N.; Ooi, T. Nat. Chem. 2014, 6, 4751. (b) Khan, A.; Zheng, R.; Kan, Y.; Ye, J.; Xing, J.; Zhang, Y. J. Angew. Chem. Int. Ed. 2014, 53, 6439-6442. (c) Khan, A.; Yang, L.; Xu, J.; Jin, L. Y.; Zhang, Y. J. Angew. Chem. Int. Ed. 2014, 53, 1125711260. See also: (d) Yang, L.; Khan, A.; Zheng, R.; Jin, L. Y.; Zhang, Y. J. Org. Lett. 2015, 17, 6230-6233.

(10) The transformation of cyclic organic carbonate into various valuable organic molecules is of our ongoing interest, see: (a) Rintjema, J.; Epping, R.; Fiorani, G.; Martín, E.; Escudero-Adán, E. C.; Kleij, A. W. Angew. Chem. Int. Ed. 2016, 55, 3972-3976. (b) Guo, W.; Gónzalez-Fabra, J.; Bandeira, N. A. G.; Bo, C.; Kleij, A. W. Angew. Chem. Int. Ed. 2015, 54, 11686-11690. (c) Laserna, V.; Fiorani, G.; Whiteoak, 
C. J.; Martin, E.; Escudero-Adán, E. C.; Kleij, A. W. Angew. Chem. Int. Ed. 2014, 53, 10416-10419.

(11) Nucleophilic attack onto vinyl cyclic carbonates has proven to be feasible, please refer to: (a) Kang, S.-K.; Kim, S.-G.; Lee, J.-S. Tetrahedron: Asymmetry 1992, 3, 1139-1140. For nucleophilic attack on the internal carbon center of the allylic intermediate: (b) Li, T.-R.; Tan, F.; Lu, L.-Q.; Wei, Y.; Wang, Y.-N.; Liu, Y.-Y.; Yang, Q.-Q. ; Chen, J.-R.; Shi, D.-Q.; Xiao, W.-J. Nat. Commun. 2014, 5, 5500.

(12) See for some illustrative examples of its use in allylic chemistry: (a) Fraunhoffer, K. J.; White, M. C. J. Am. Chem. Soc. 2007, 129, 7274-7276. (b) Stang, E. M.; White, M. C. Nat. Chem. 2009, 1, 547551. (c) Young, A.; White, M. C. J. Am. Chem. Soc. 2008, 130, 1409014091. Please also see ref. 5e.

(13) The lower isolated yield is a consequence of a competitive side reaction that involves aminolysis of the cyclic carbonate by the amine reagent which was indeed observed as a side-product. Such aminolysis behavior has been well-documented, see e.g. reference 10b. See also: Blain, M.; Jean-Gérard, L.; Auvergne, R.; Benazet, D.; Caillol, S.; Andrioletti, B. Green Chem. 2014, 16, 4286-4291.

(14) In the presence of other bases, amines and aryl halides may react to give the cross-coupled arylamine products under palladium catalysis known as "Buchwald-Hartwig Cross Coupling", see for representative examples: (a) Fors, B. P.; Krattiger, P.; Strieter, E.; Buchwald, S. L. Org. Lett. 2008, 10, 3505-3508. (b) Fors, B. P.; Buchwald, S. L. J. Am. Chem. Soc. 2010, 132, 15914-15917. Addition of external base may also lead to 1,2-diol (reference 10c) or carbamate (reference 10b) formation.

(15) Dai, J.; Wang, M.; Chai, G.; Fu, C.; Ma S. J. Am. Chem. Soc. 2016, 138, 2532-2535.

(16) For some examples of allylic substitution reactions under thermodynamic control see: (a) Steinhuebel, D.; Palucki, M.; Davies, I. W. J. Org. Chem. 2006, 71, 3282-3284. (b) Wang, C.; Tunge, J. A. Org. Lett. 2006, 8, 3211-3214. (c) Trost, B. M.; Machacek, M. R.; Tsui, H. C. J. Am. Chem. Soc. 2005, 127, 7014-7024.

(17) The carbonate precursor was derived from a commercially available (40:60 ratio) alkene mixture. See the Supporting Information for further details.

(18) See the Supporting Information for details.

(19) Note that typically the thermodynamically favored $(E)$-isomer of the $\gamma$-mono-substituted allylic amines is observed, refer to references 3-5. An additional control experiment was carried with vinyl epoxide as an alternative substrate, and this was treated with 2,6-di-isopropylaniline under similar conditions as reported for the synthesis of $\mathbf{4 8}$. The crude reaction mixture showed the presence of only trace amounts of 48 together with other species underlining the importance of the nature of the substrate towards highly selective formation of the allylic amine target. See Supporting Information for more details.

(20) Representative examples include: (a) Taillemaud, S.; Diercxsens, N.; Gagnon, A.; Charette, A. B. Angew. Chem. Int. Ed. 2015, 54 , 14108-14112. (b) Chen, H.; Kaga, A.; Chiba, S. Org. Biomol. Chem. 2016, 14, 5481-5485. (c) He, Z.; Wibbeling, B.; Studer, A. Adv. Synth. Catal. 2013, 355, 3639-3647. (d) Rama, R. N; Soni, V. K. Adv. Synth. Catal. 2015, 358, 276-282. (e) He, Z.; Kirchberg, S.; Fröhlich, R.; Studer, A. Angew. Chem. Int. Ed. 2012, 51, 3699-3702. (f) Zhang, C.; Santiago, C. B.; Crawford, J. M.; Sigman, M. S. J. Am. Chem. Soc. 2015,
137, 15668-15671. (g) Zhang, C.; Santiago, C. B.; Crawford, J. M.; Sigman, M. S. J. Am. Chem. Soc. 2015, 137, 15668-15671. (h) Zhu, S.; Niljianskul, N.; Buchwald, S. L. Nat. Chem. 2016, 8, 144-150.

(21) (a) Akermark, B.; Bäckvall, J.-E.; Löwenborg, K.; Zetterberg, K. J. Organomet. Chem. 1979, 166, C33. (b) Bäckvall, J. E. Acc. Chem. Res. 1983, 16, 335-342. See also references $7 \mathrm{a}$ and 7f.

(22) (a) Sperger, T.; Sanhueza, I. A.; Kalvet, I.; Schoenebeck, F. Chem. Rev. 2015, 115, 9531-9586. (b) Mora, G.; Piechaczyk, O.; Le Goff, X. F.; Le Floch, P. Organometallics 2008, 27, 2565-2569.

(23) Balcells, D.; Maseras, F. New J. Chem. 2007, 31, 333-343.

(24) (a) Whiteoak, C. J.; Nova, A.; Maseras, F.; Kleij, A. W. ChemSusChem 2012, 5, 2032-2038. (b) Schmeier, T. J.; Nova, A.; Hazari, N.; Maseras, F. Chem. Eur. J. 2012, 18, 6915-6927. (c) CastroGomez, G.; Salassa, G.; Kleij, A. W.; Bo, C. Chem. Eur. J. 2013, 19, 6289-6298. (d) Jover, J.; Maseras F. J. Org. Chem. 2014, 79, 1198111987.

(25) (a) Li, H.; Hall, M. B. J. Am. Chem. Soc. 2014, 136, 383-395. (b) Li, H.; Hall, M. B. J. Am. Chem. Soc. 2015, 137, 12330-12342. (c) Yuan, R.; Lin, Z. ACS Catal. 2015, 5, 2866-2872

(26) See the Supporting Information for full computational details.

(27) Note that experimentally the formation of $(Z)$ allylic amine $\mathbf{4 0}$ requires a longer reaction time than suggested by the energetic span $(12.0 \mathrm{kcal} / \mathrm{mol}$ ) computed for its formation (Figure 8). However, the calculation starts off with a $\operatorname{Pd}(0)$ catalyst and the formation of the latter from $\mathrm{Pd}(\mathrm{II})$ acetate precursor in the presence of excess phosphine has been reported previously to be more energy demanding. See: (a) Amatore, C.; Carré, E.; Jutand, A.; M'Barki, M. A. Organometallics 1995, 14, 1818-1826. See also: (b) Amatore, C.; Jutand, A.; Thuilliez, A. Organometallics 2001, 20, 3241-3249. (c) Wei, C. S.; Davies, G. H. M.; Soltani, O.; Albrecht, J.; Gao, Q. Angew. Chem. Int. Ed. 2013, 52, $5822-5826$

(28) We also considered the option of the PhNH amide group binding to the metal but such a pathway also resulted in significantly higher energies and therefore seems unlikely (see Supporting Information, Figure S6)

(29) For a discussion of syn/anti isomerism of $\pi$-allyl-Pd scaffolds: (a) Trost, B. M.; Machacek, M. R.; Aponick, A. Acc. Chem. Res. 2006, 39, 747-760. (b) Ogasawara, M.; Takizawa, K.; Hayashi, T. Organometallics 2002, 21, 4853-4861. (c) Tsuji, J. Pure Appl. Chem. 1982, 54, 197-206. (d) Hayashi, T.; Kawatsura, M.; Uozumi, Y. J. Am. Chem. Soc. 1998, 120, 1681-1687.

(30) $\mathrm{CO}_{2}$ extrusion from intermediate $\mathbf{t 1 7}$ to form an epoxide intermediate $\mathbf{t 1 8}$ reminiscent of $\mathbf{t} \mathbf{9}$ was also considered but the barrier of $\mathbf{t}(\mathbf{1 7 - 1 8})^{\frac{1}{a}}$ at $-0.8 \mathrm{kcal} / \mathrm{mol}$ lies significantly higher in energy than $\mathbf{t}(\mathbf{4}$ 5) ${ }^{\ddagger}$ at $-7.4 \mathrm{kcal} / \mathrm{mol}$ leading to the six-membered palladacycle $\mathbf{t 5}$. See Supporting Information (Figure S7) for more details.

(31) Similar observations regarding substituent effects on substrate reactivity were noted in related allylic chemistry: Trost, B. M.; Bunt, R. C.; Lemoine, R. C.; Calkins, T. L. J. Am. Chem. Soc. 2000, 122, 5968-5976.

(32) Álvarez-Moreno, M., de Graaf, C.; López, N.; Maseras, F.; Poblet, J. M.; Bo, C. J. Chem. Inf. Model. 2015, 55, 95-103. 
SYNOPSIS TOC:

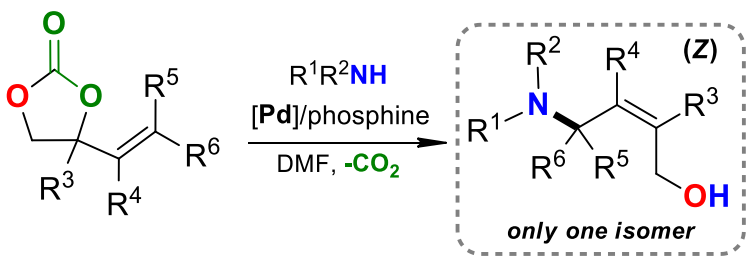

- Mild conditions, operationally simple

- Highly stereo-selective, open to air

- No additives needed, 43 examples 